\title{
Narratives in Oncology
}

\section{Don S. DIZoN}

Massachusetts General Hospital, Boston, Massachusetts, USA

Disclosures of potential conflicts of interest may be found at the end of this article.

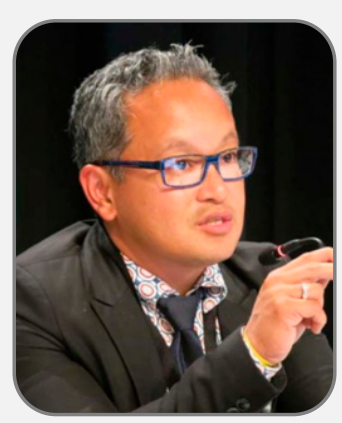

Dr. Don S. Dizon
As so many others do, I have my smartphone set to alert me when a new e-mail arrives in any of my inboxes (yes, I have several). This message was special, though: it was an e-mail from Lecia Sequist, a colleague and Deputy Editor of The Oncologist, asking whether I would be interested in helming a section of the journal on personal essays. Even before I spoke to her in person, I knew I would do it.

The Oncologist has already devoted space to personal pieces, with many centered on the Schwartz Rounds of the Massachusetts General Hospital Cancer Center, those forums where clinicians, patients, and caregivers meet and share their experiences in health care. I have often read them, touched by the diverse voices embodied in these articles. How could I help to broaden the scope of this endeavor?

For me, the answer was quite apparent: I could use this space to help stimulate conversation and facilitate the lifelong learning of humanism in oncology. That is, I could use this space to document narratives in oncology. I am not new to narratives. I am a regular contributor to ASCO Connection, the professional networking site of the American Society of Clinical Oncology, and I routinely immerse myself in personal biographies, both inside and outside of medicine. My eyes are often drawn first to the personal pieces in the many journals I review published by our peers. I suppose it has been this way for me since medical school at the University of Rochester, where the art of medicine was part of the curriculum, and exposure to works by Paul Monette and Maya Angelou was a part of my medical training. Indeed, I recently published a column on narrative medicine in ASCO Connection. It was a call to others to tell their stories. Whether it be an important lesson or a deeper understanding experienced, I think we all have something to share.

Therefore, I want to call for submissions to this new section, from physician to nurse and advanced practice provider to caregiver and patient. My hope is to publish pieces that go beyond the retelling of a story by addressing this question head-on: "What's my point?" I want to hear what others should learn from you and what your story should tell us. As Abigail Adams said, "Wisdom and penetration are the fruit of experience, not the lessons of retirement and leisure. Great necessities call out great virtues."

Ultimately, oncology is an extreme human experience for us all. As such, hearing how we all experience it is important, and all of our stories matter. This section will highlight what we've been through and what others can take away from our experiences.

This is a call for narratives in oncology, and we are very interested in yours.

DISCLOSURES

The author indicated no financial relationships. 